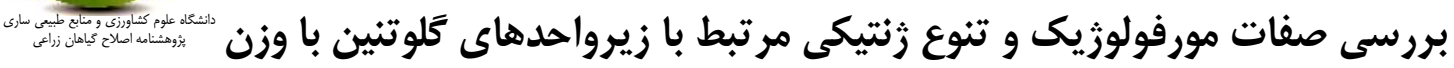

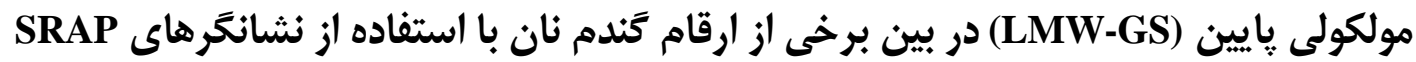

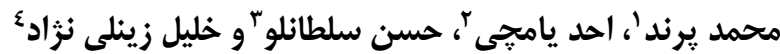

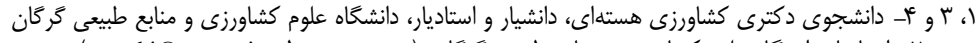

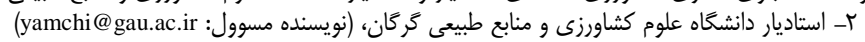

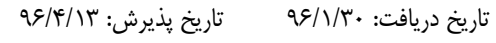

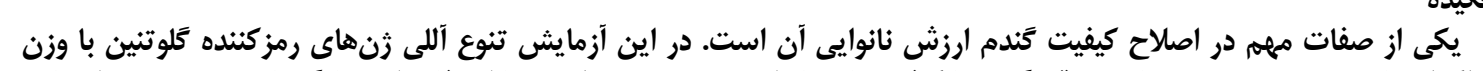

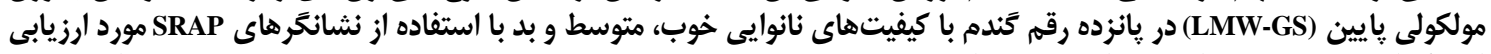

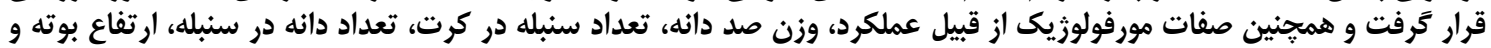

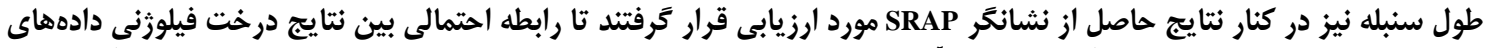

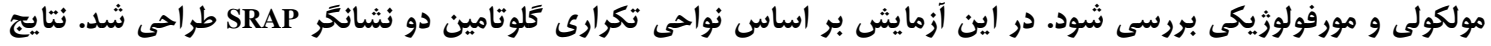

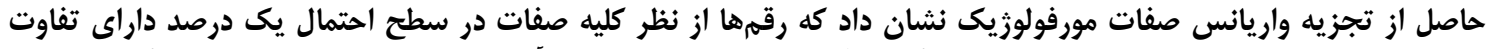

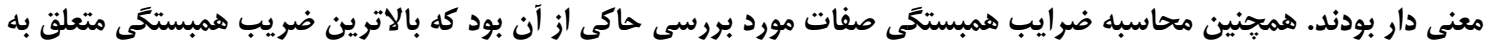

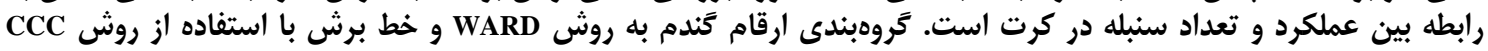

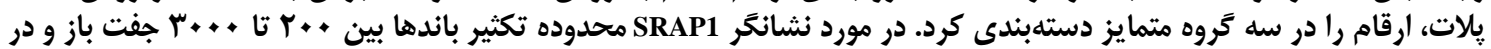

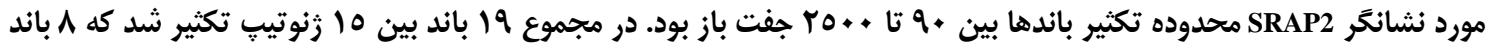

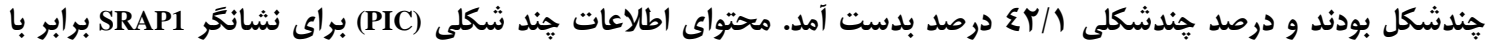

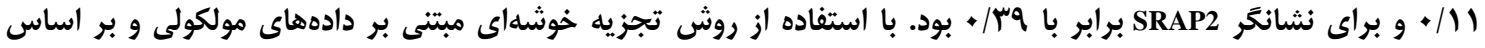

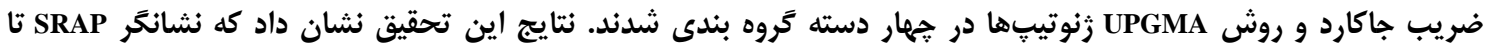

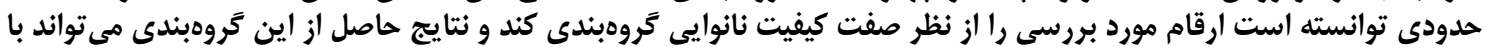
نتايج حاصل از دادههاى موروفولوزيك مورد مقايسه قرار بحتيرد.

وازههاى كليدى: كَندم نان، كيفيت نانوايى، صفات مورفولوزيك و نشانتر SRAP

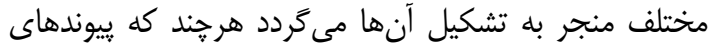

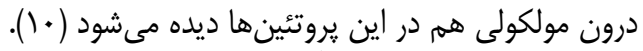

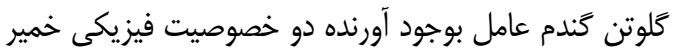

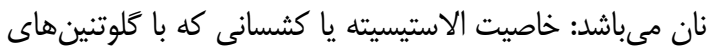

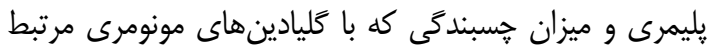

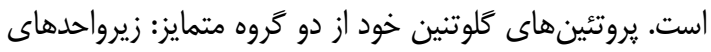

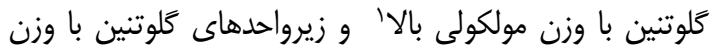

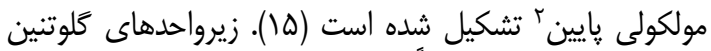

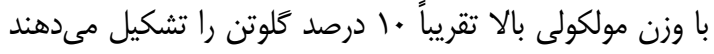

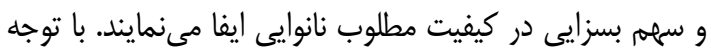

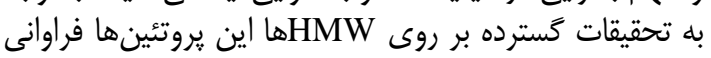

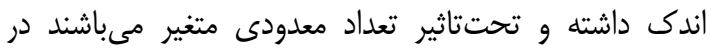

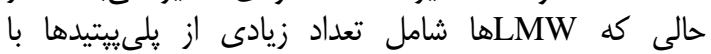

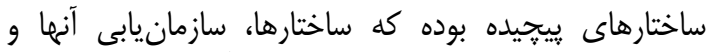

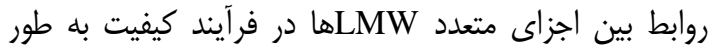

كامل شناسايى نشده است (•) (1). توسط زنهاى موجود بر روى بازوى كوتاه

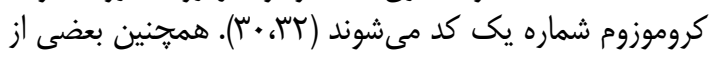

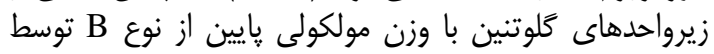

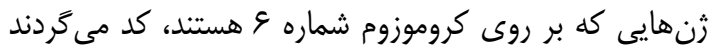

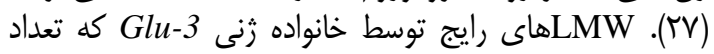

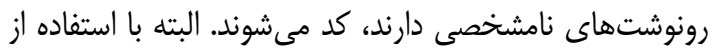

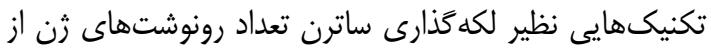
1- High Molecular Wight-Glutenin Subunits
مقدمه

كندم نان (Triticum aestivum L.) با بيش از هزار كزاران

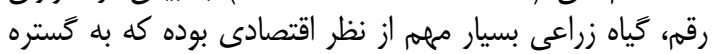

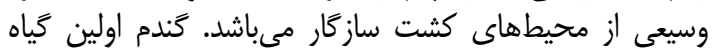

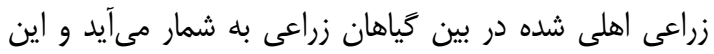

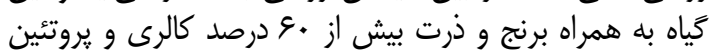

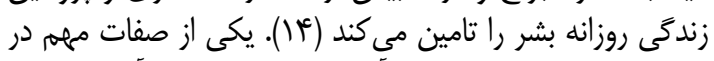

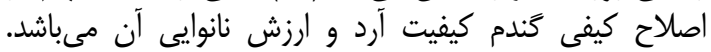

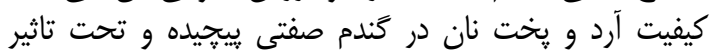

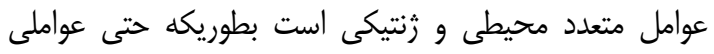

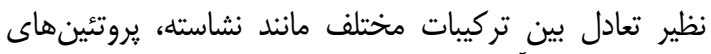

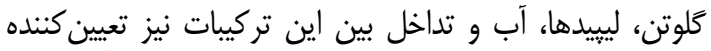

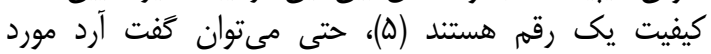

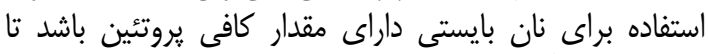
خمير بدست آمده خصوصيت كاركردى مناسبى ران را داشته باشد باند

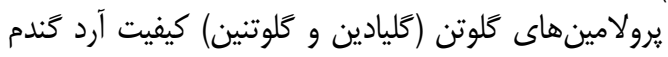

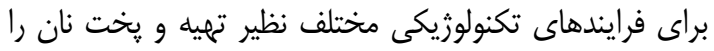

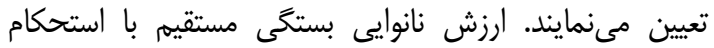

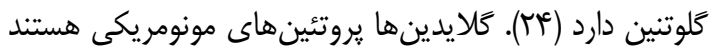

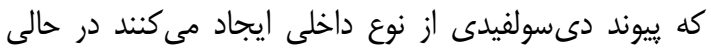

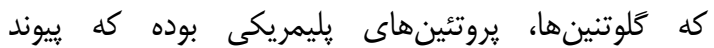
دىسولفيدى (از نوع بين مولكولى) مابين زير واحدهاى 
يشت سر هم كَلوتامين) و ناحيه با توالى حفاظت شدهى بإيانه

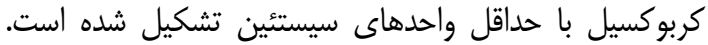

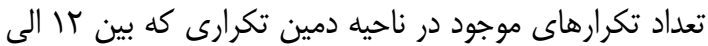

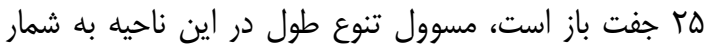

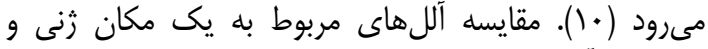

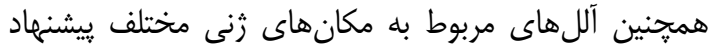

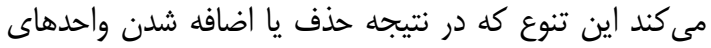

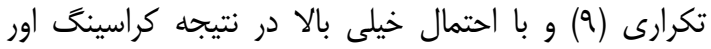

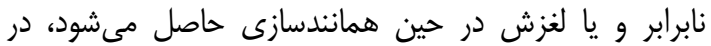

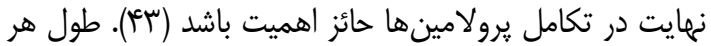

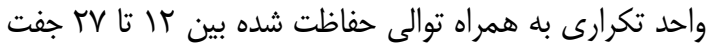

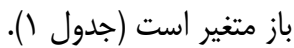

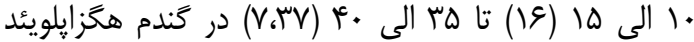

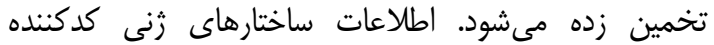

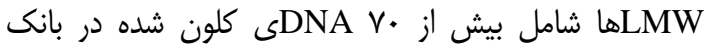

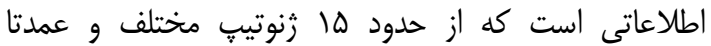

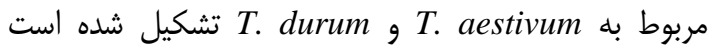

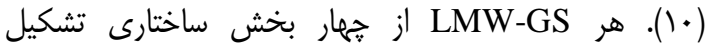

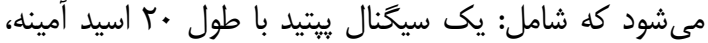

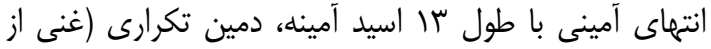

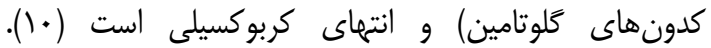

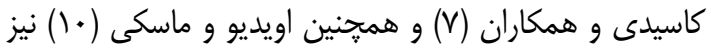

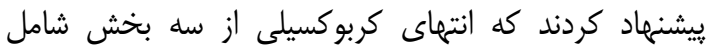

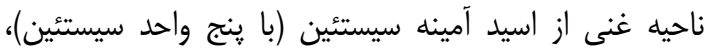
ناحيه غنى از كلوتامين (با يك واحد سيستئين و واحدهاى لئي

جدول ا- توالىهاى حفاظت شده در ناحيه تكرارى ساختار LMW-GS (1) Table 1. Conserved sequence in repetitive domain of LMW-GS structure (10)

\begin{tabular}{|c|c|c|}
\hline توالى اسيد آمينه نواحى حفاظت شده & توالى حفاظت شدهى نواحى تكرارى در ساختار LLMW-GS & شماره دسترسى در بانكى زن \\
\hline PPFSQQ & 5'CCACCATTTTCACAA3' & U86028 \\
\hline PPFSQQQQ & 5'CCACCATTTTCACAGCAACAACAA3' & AB062878 \\
\hline PPFSQQQQ & 5'CCACCATTTTCGCAACAACAACAA3' & Y17845 \\
\hline
\end{tabular}

مورد استفاده قرار كرفت. اين نشانكر توالىهاى كد كننده در

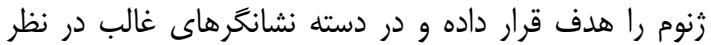

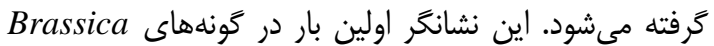

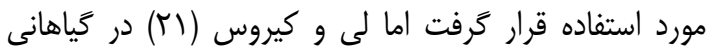

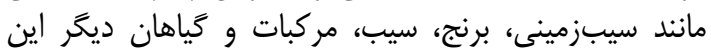

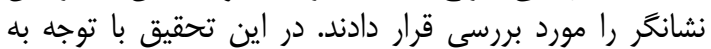

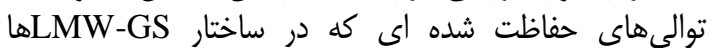

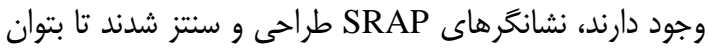

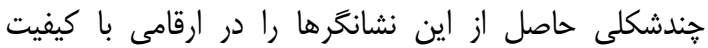

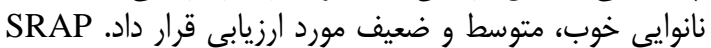

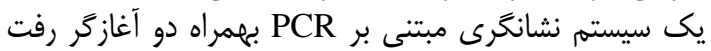

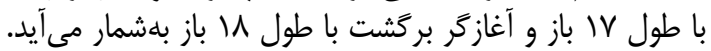

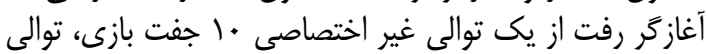

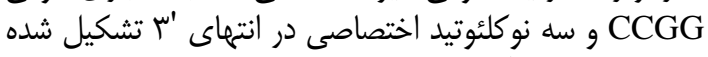

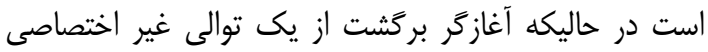

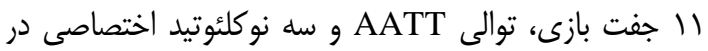

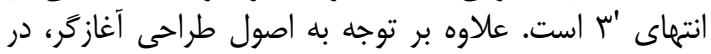

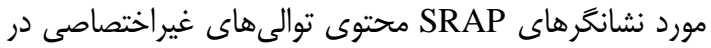

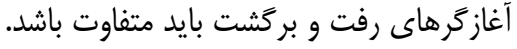

\section{مواد و روشها}

مواد كَياهى مورد استفاده در اين آزمايش شامل

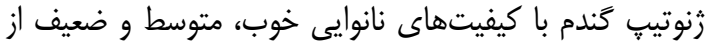

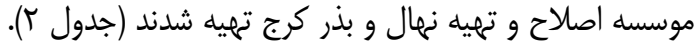

طراحى آغازگر از ناحيه حفاظت شده اگزونى مىتواند منجر

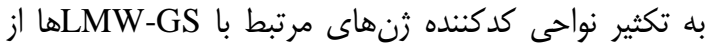

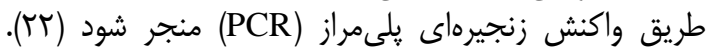

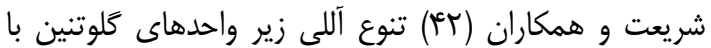

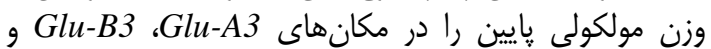

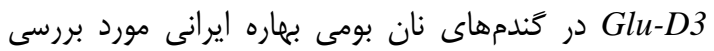
قرار دادند. در اين تحقيق براى مكانهاى Glu

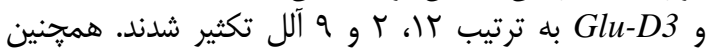

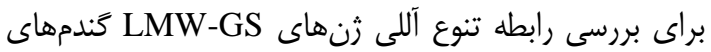

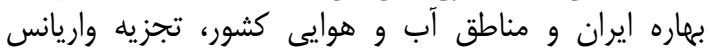

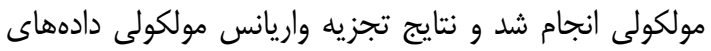

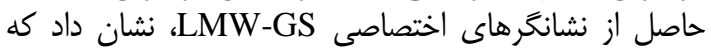

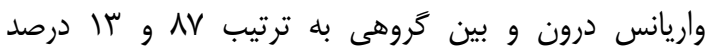

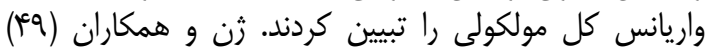

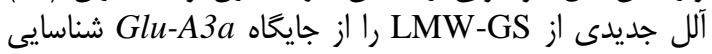

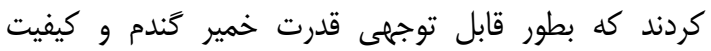
نانوايى را كنترل مي كنمود.

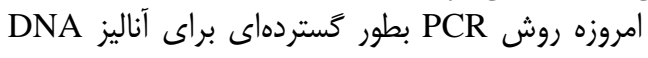

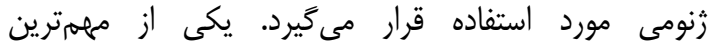

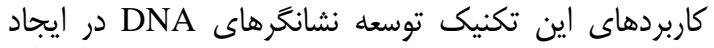

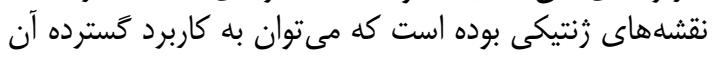

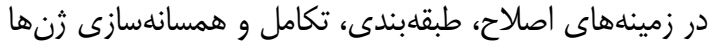

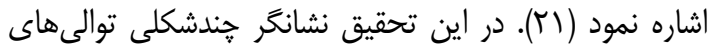

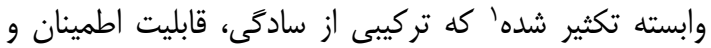

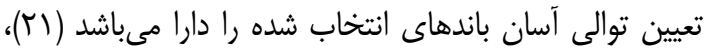


Table 2. Specifications of genotypes used

جدول r- مشخصات زنوتيِهاى استفاده شده (q")

\begin{tabular}{|c|c|c|c|c|c|c|}
\hline كيفيت نانوايى & ميانكَين درصد & عملكرد (كيلوكَرم & ميانكين وزن هزار) & اقليم و شرايط كشت & معرفى سل & رنوتيبها \\
\hline خوب & r & is.. & $\mu N / \Delta$ & گرم و مرطوب شمال & (W9D & كلمتان \\
\hline خيلى خوب & ir & Q9Y. & is & مزارع آبى معتدل & $1 \% q$. & سيروان \\
\hline خيلى خوب & ir & $\Lambda \triangle \wedge 1$ & - & معتدل & IrM & 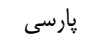 \\
\hline متوسط تا خوب & $1 \cdot / V$ & rqq. & ( ) & اقليمهاى معتدل & $\mid r \Delta \Lambda$ & آزادى ل \\
\hline ضعيف & it & GTQ. & rı & كَرمسير و نيمه كرمسير & a & 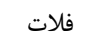 \\
\hline متوسط & $1 . / r$ & $\Delta \Delta \cdots$ & rV & كر كسير & irv. & هيرمند \\
\hline خوب & ir & s... & ru & جلكَهاى ساحل خزر & IrVF & تجن \\
\hline خوب & $1 \% / \Delta$ & $g V .$. & $r v$ & معتدل & irre & 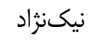 \\
\hline خوب & $1 \% / \Delta$ & $\Delta \wedge . \cdot$ & $r \Delta / \Delta$ & كرم جنوب & IrVt & اترك \\
\hline متوسط & 1.10 & $\Delta V_{*} \cdot$ & ru & شور و كم آب & ITVE & كوير \\
\hline ضعيف & $1 . / 4$ & $90 .$. & $\mu N / \Delta$ & سواحل درياى خزر & IrVG & شيرودى \\
\hline خوب & $11 / 0$ & $v_{*} \cdot \cdot$ & $\kappa e / \Delta$ & مناطق معتدل & $|r|$ & ي يشتاز \\
\hline ضعيف & 1.11 & $S \mid Q$. & ru & كرم جنوب & $|r|$ & 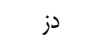 \\
\hline ضعيف & $11 / \mathrm{V}$ & SIOT & r & كرم و مرطوب شمال & IrM & مرواريد \\
\hline متوسط & $1 . / 94$ & $99 v 9$ & - & معتدل & (IMN & بهار \\
\hline
\end{tabular}

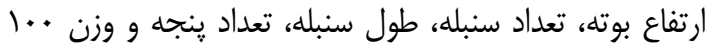

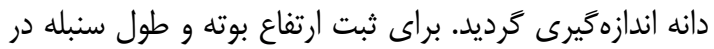

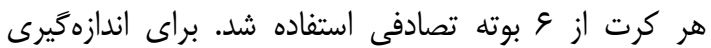

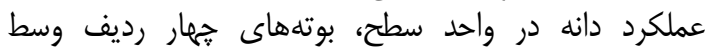

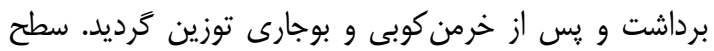

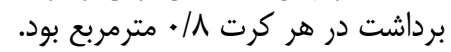

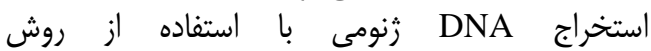
تازه كندم

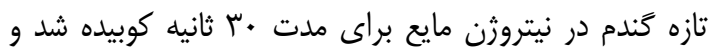

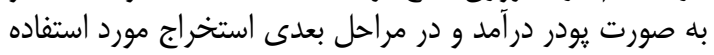

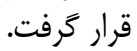

آزمايش در قالب طرح بلوكهاى كامل تصادفى با سه

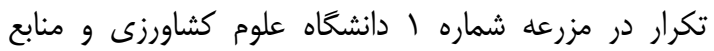

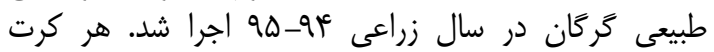

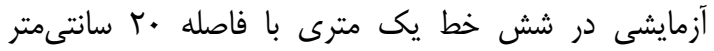

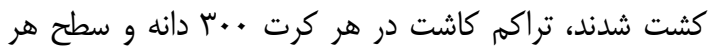

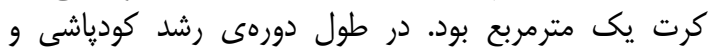

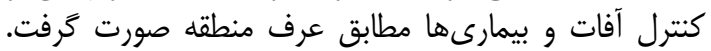

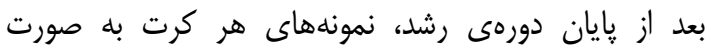

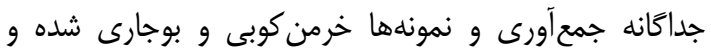

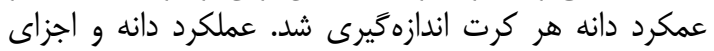

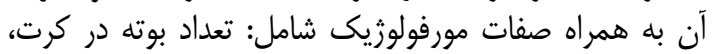

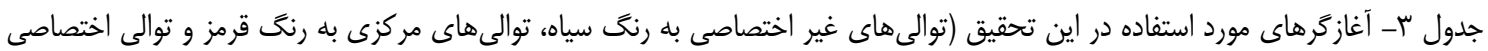

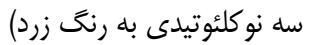

Table 3. Primers used in this study (non-specific sequences in black, the central sequences in red and specific sequence yellow)

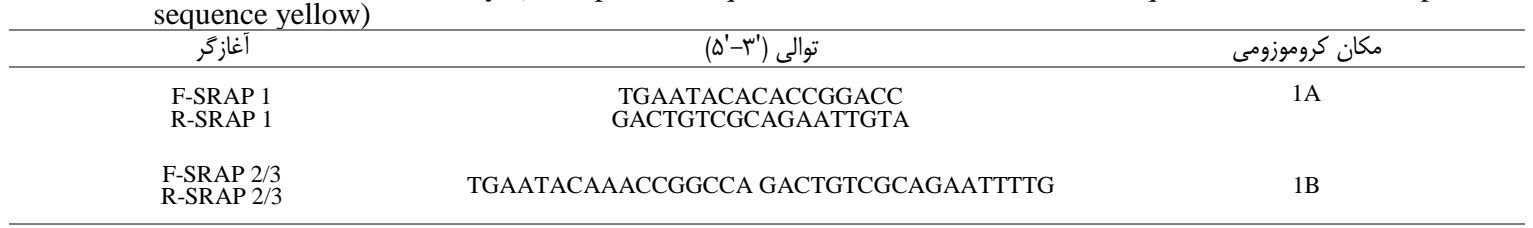

زنومى انجام شد. برنامه PCR با واسرشتسازى اوليه در

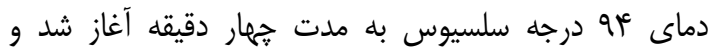

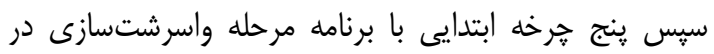

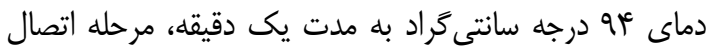

در حجم نهايى ·ل ميكروليتر حاوى ه ميكروليتر PCR

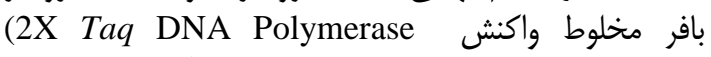
Master Mix RED)

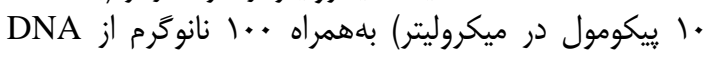


درصد بود. همجنين در مورد تعداد سنبله در كرت، رقمم IV/9I

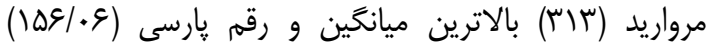

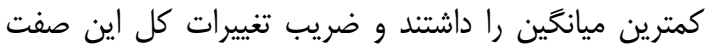

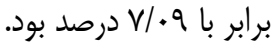

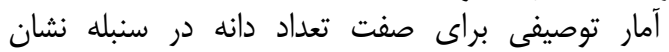

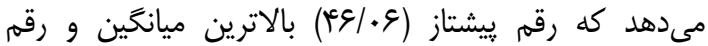

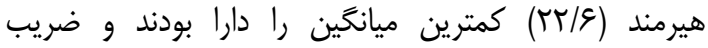

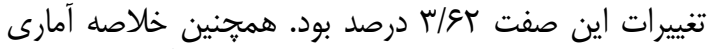

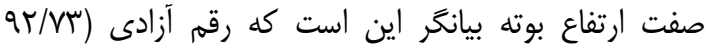

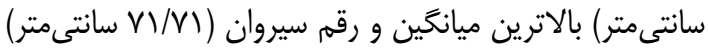

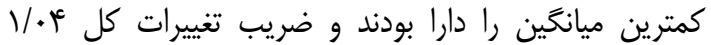

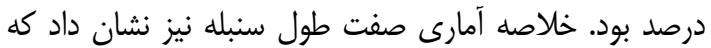

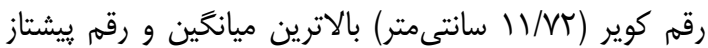

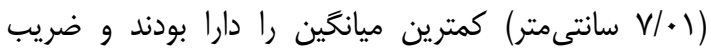

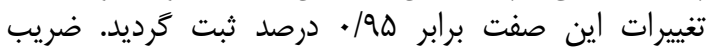

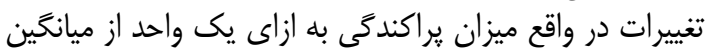

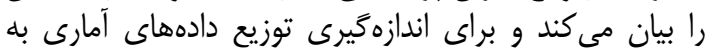

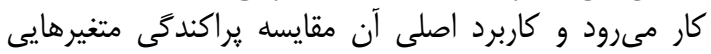

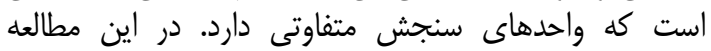
مشخص شد كه كمترين ضريب تغييرات فنوتييى مربوط به به مانه

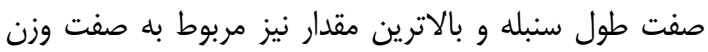

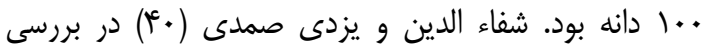

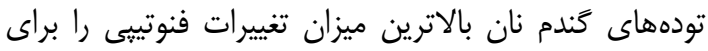

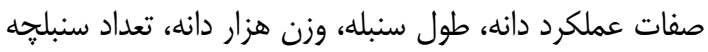

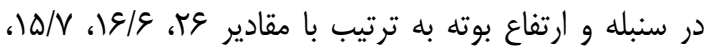

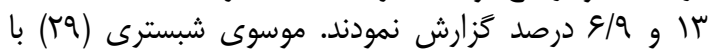

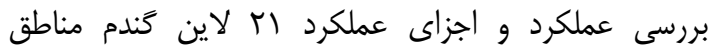

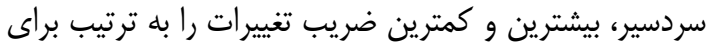

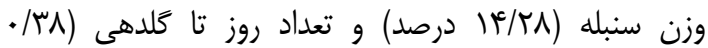

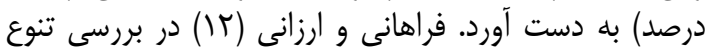

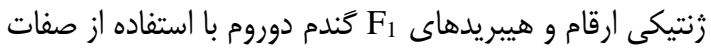

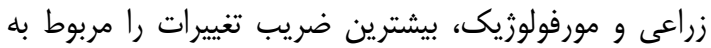

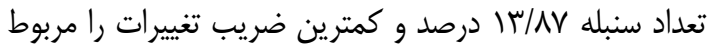

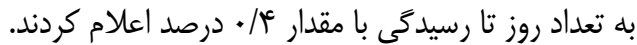

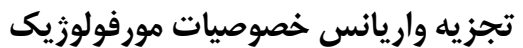

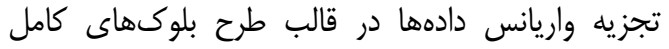

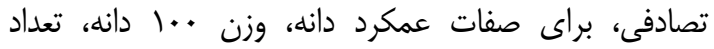

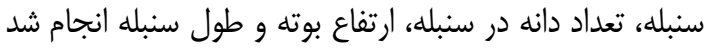

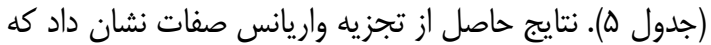

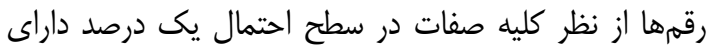

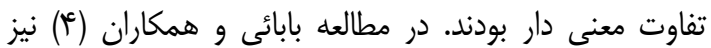

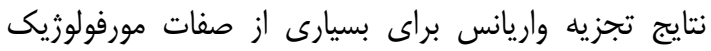

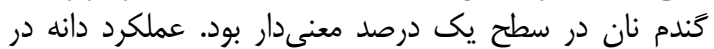

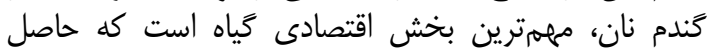

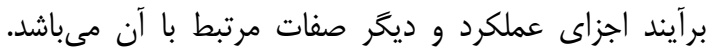

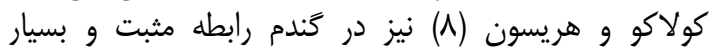

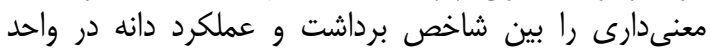

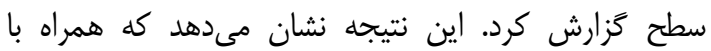
افزايش عملكرد دانه، نسبت عملكرد اقتصادى نيجه به به عملكرد
در دماى هץ درجه سانتى گراد به مدت يك دقيقه و دو مرحله

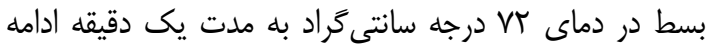

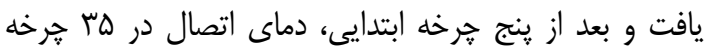

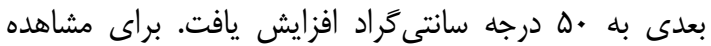

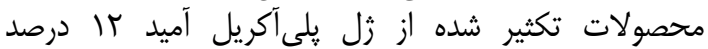

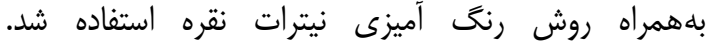

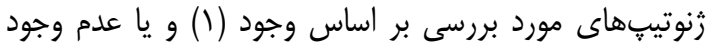

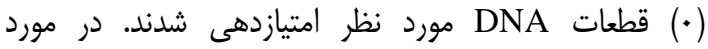

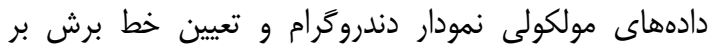

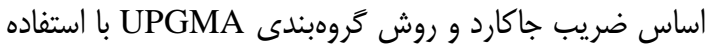

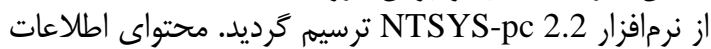

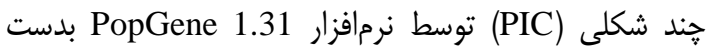

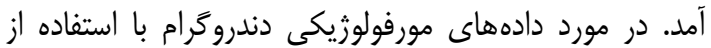

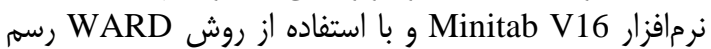
گرديد. براى تعيين خط برش نيز از نرمافزار روش CCC پيلات (r) استفاده شد.

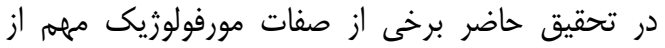

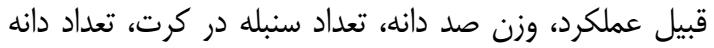

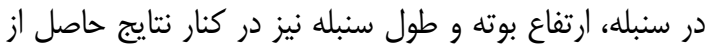

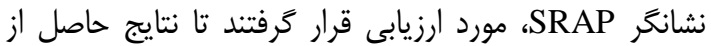

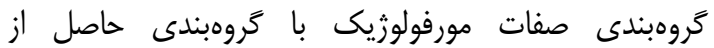

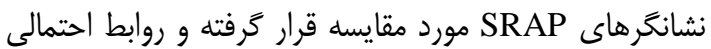

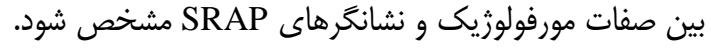
نتايج دادههاي فنوتيبى آمارههاى توصيفى (جدول ثاد فئ) در مورد صفت عملكرد دانه

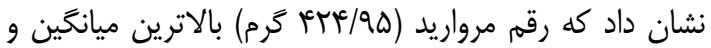

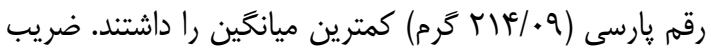

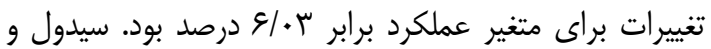

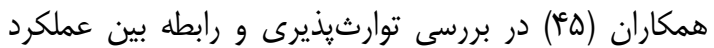

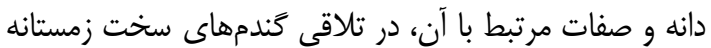

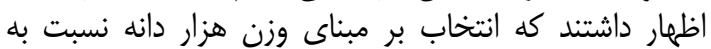

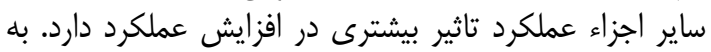

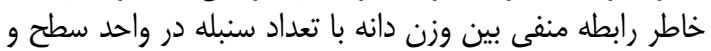

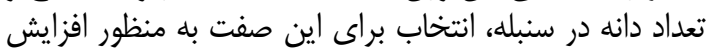

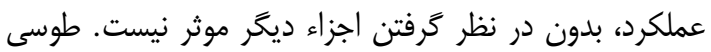

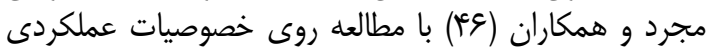

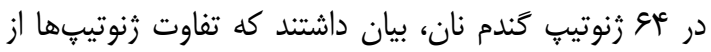

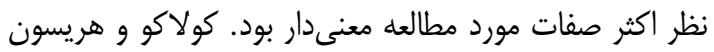

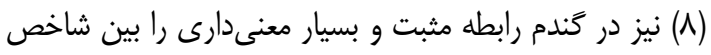

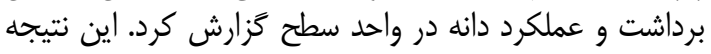

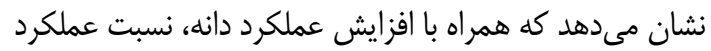

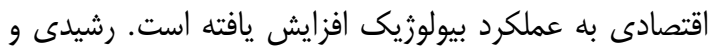

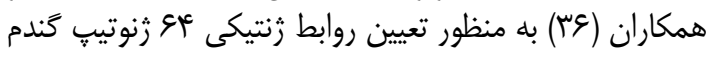
دوروم را مورد بررسى قرار به منظور دادند.

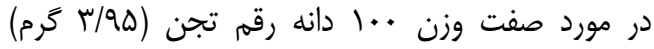

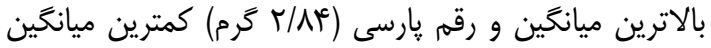

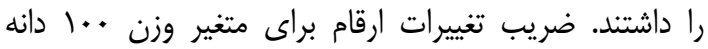


باشند. ظرفيت عملكرد دانه به توانايى رنوتيٍ در ساخت، انتقال

و ذخيره مواد غذايى در دانه بستخى دارد (بّ).
بيولوزيك افزايش يافته است. يكى از اهداف اصلى در اصلاح كُندم، توليد ارقامى است كه داراى ظرفيته إنيت توليد بيشترى

جدول عا- آمارههاى توصيفى عملكرد دانه و خصوصيات مورفولوزيك ارقام گندم Table 4. Descriptive statistics for grain yield and morphological traits in wheat cultivars

\begin{tabular}{|c|c|c|c|c|}
\hline ضريب تغييرات (\%) & حداقل & حداكثر & ميانگين & نوع صفت \\
\hline $9 / \cdot r$ & $r \mid 4 / .9$ & FTY/QD & $r I . / V T$ & عملكرد دانه (كرم در كرت) \\
\hline$|V / 9|$ & $r / A F$ & $r / 9 \Delta$ & $r / \mp \wedge$ & وزن ... ادانه (كرم) \\
\hline$v / .9$ & 1091.9 & 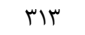 & ג•ונוז & تعداد سنبله در كرت \\
\hline$r / q r$ & $r T / Q$ & $\mid 91.9$ & $r \cdot / r q$ & تعداد دانه در سنبله \\
\hline $1 / \cdot 4$ & $V I / V I$ & $9 \% / V T$ & $\Lambda T / . r$ & ارتفاع بوته (سانتىمتر) \\
\hline.$/ 9 \Delta F$ & $\mathrm{~V} / \cdot \mathrm{I}$ & $11 / V T$ & q/q & طول سنبله (سانتىمتر) \\
\hline
\end{tabular}

جدول ه- نتايج تجزيه واريانس عملكرد دانه و خصوصيات مورفولوزيك ارقام كندم Table 5. Analysis of variance for grain yield and morphological traits in wheat cultivars

\begin{tabular}{|c|c|c|c|c|c|c|c|}
\hline طول سنبله & ارتفاع بوته & تعداد دانه در سنبله & ت تعداد سنبله & وزن .. 1 دانه & عملكرد & درجه آزادى & منابع تغيير \\
\hline.$/ \cdot 11^{\mathrm{ns}}$ & $\cdot / 019^{\text {ns }}$ & $\cdot / \mathrm{rvq}^{\mathrm{ns}}$ & $\Delta q / \mathrm{rn}^{\mathrm{ns}}$ & $\cdot / \cdot 11^{\mathrm{ns}}$ & $r \cdot q / v^{\mathrm{ns}}$ & $r$ & بلوى \\
\hline$f / V^{w}$ & 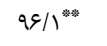 & $1 . f^{* * * n}$ & $9 \times 99 / \Lambda^{* * m}$ & $\cdot / T h f^{*}$ & $r \cdot 99 / 1^{* * 3}$ & 15 & رقم \\
\hline $.1 . .9$ & r & $1 / \pi \cdot 9$ & TEN/G & q & rol/q & $r \Lambda$ & خطا \\
\hline
\end{tabular}

معنى دارى دور از انتظار نبود زيرا با افزايش تعداد سنبله، تعداد

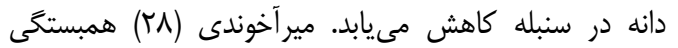

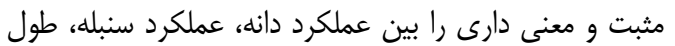

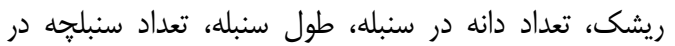
سنبله، وزن سنبله و وزئن هزار دار دانه دز

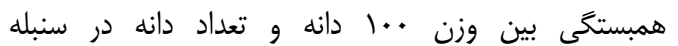

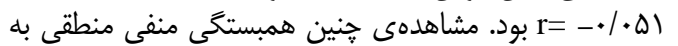

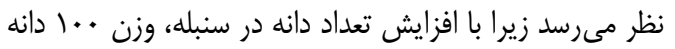

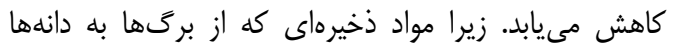

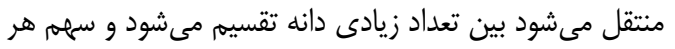

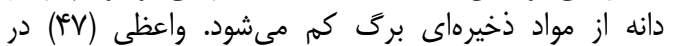

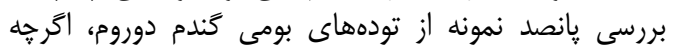

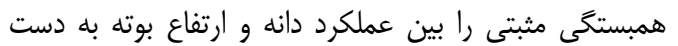

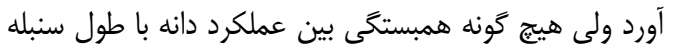

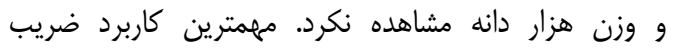

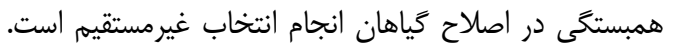

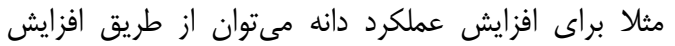

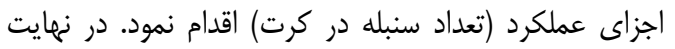

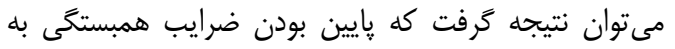

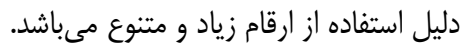

ضرايب همبستخى

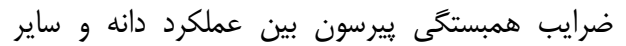

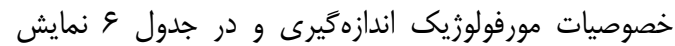

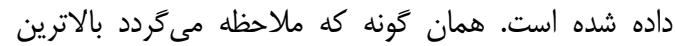

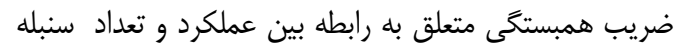

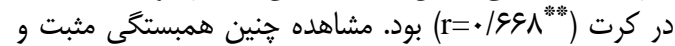

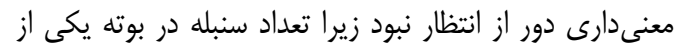

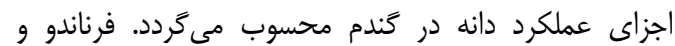

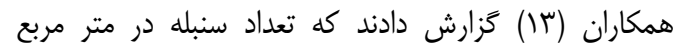

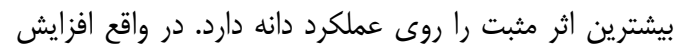

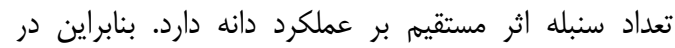

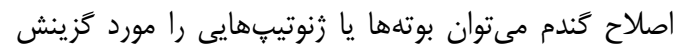

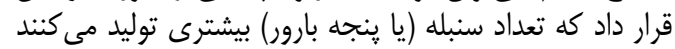

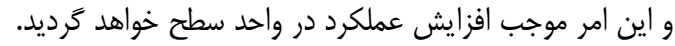

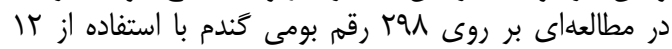

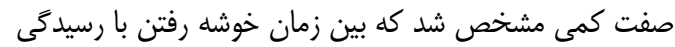

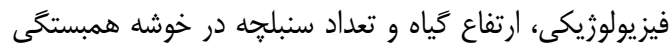

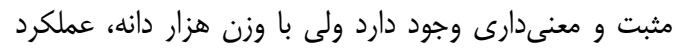

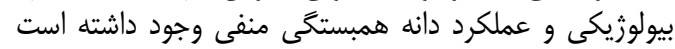

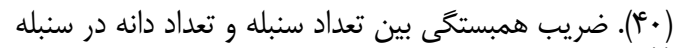

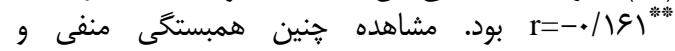

جدول צ- ضرايب همبستخى خصوصيات مورفولوزيك ارقام كندم مورد بررسى Table 6. Correlation coefficients for morphological traits of the wheat cultivars

\begin{tabular}{|c|c|c|c|c|c|c|}
\hline طول سنبله & تعداد دانه در سنبله & ارتفاع كَياه & تعداد سنبله در كرت & وزن صد دانه & عملكرد دانه & \\
\hline & & & & & 1 & عملكرد دانه \\
\hline & & & & 1 &.$/ 4 \wedge 9$ & وزن صد دانه \\
\hline & & & 1 &.$/ F Y g^{* * 0}$ & $.199 \Lambda^{* * 4}$ & تعداد سنبله در كرت \\
\hline & & 1 &.$- / .4 r$ & $\cdot / r \cdot V$ &.$/ 19$ & ارتفاع كياه \\
\hline & 1 &.$/ .14$ &.$- \mid 191$ &.$-|\cdot \Delta|$ & 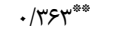 & تعداد دانه در سنبله \\
\hline 1 & $-\cdot / \Delta V^{* * a}$ & $-\cdot / r \cdot V$ &.$/ 191$ & $\cdot / T \Delta \Delta$ & - $\cdot / \mu \cdot \mu^{*}$ & طول سنبله \\
\hline
\end{tabular}


كيفيت نانوايى ضعيف مطرح هستند، از نظر هفت صفت

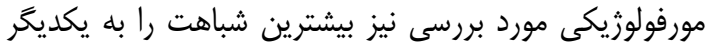

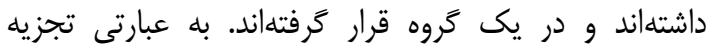

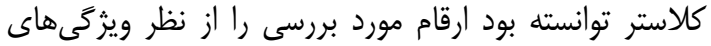

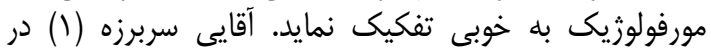

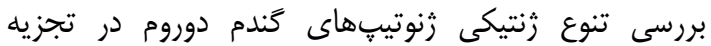

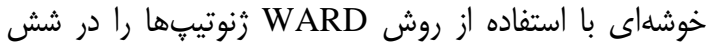

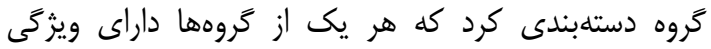
خاصى از جمله يتانسيل عملكرد، تعداد دانه در در سنبله

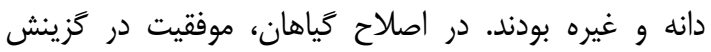

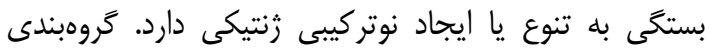

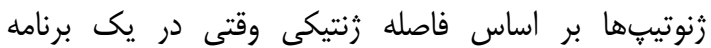

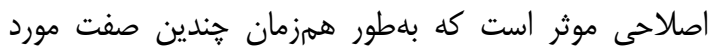

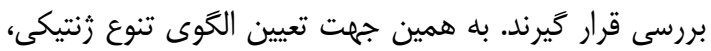

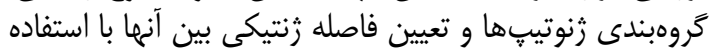
از خوشهاى انجام مى خيردي
كَروهبندى ارقام كَندم بر اساس صفات مورفولوزيكى

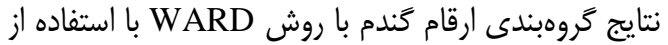

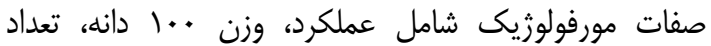

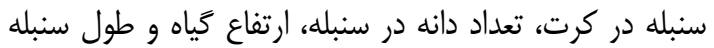

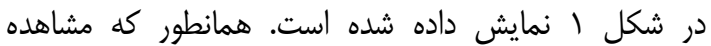

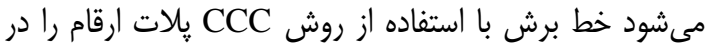

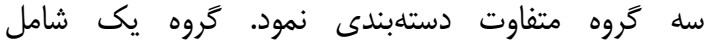

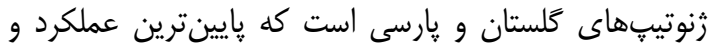

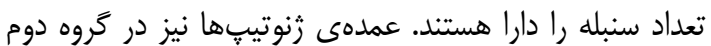

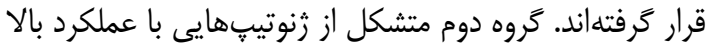

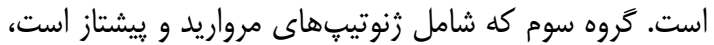

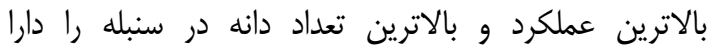

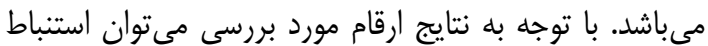

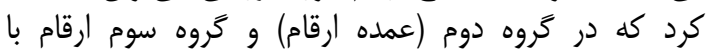

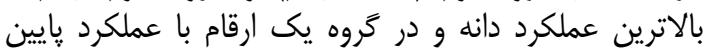

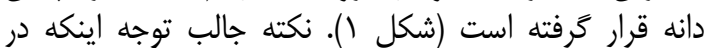

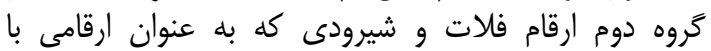

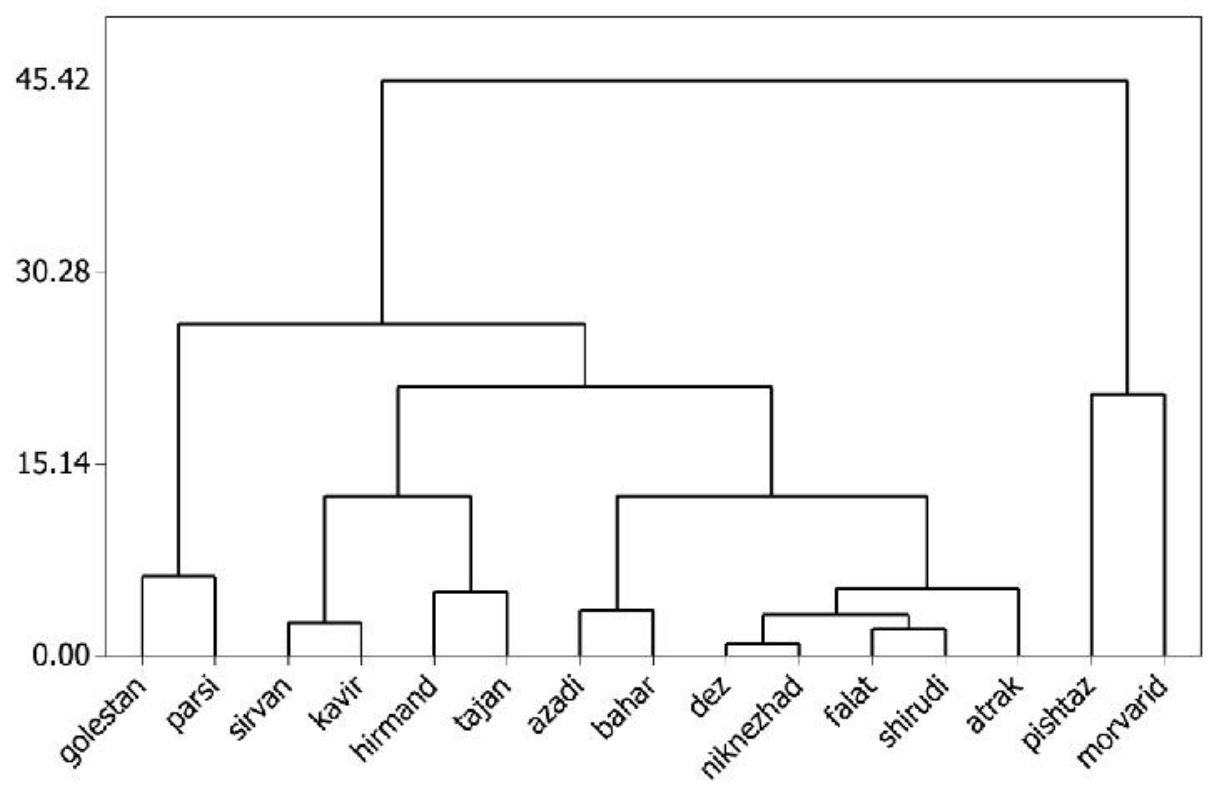

شكل ا- دندروگرام ارقام بر اساس دادههاى مورفولوزيك با استفاده از روش WARD

Figure 1. Dendrogram based on morphological data using WARD method

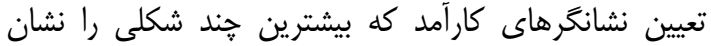

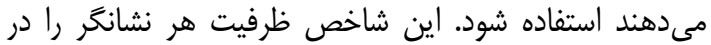

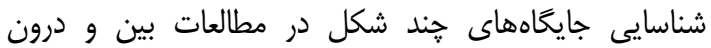

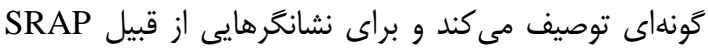

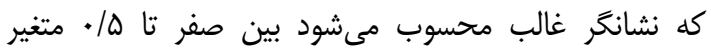

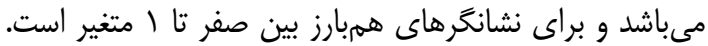

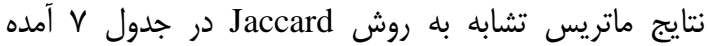

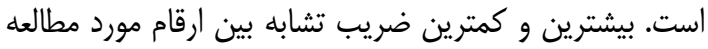

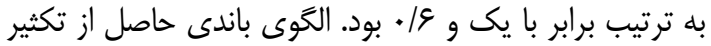

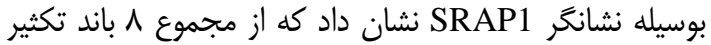

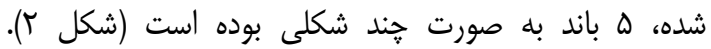

تجزيه و تحليل دادههاى مولكولى تنى تُوني

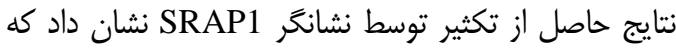

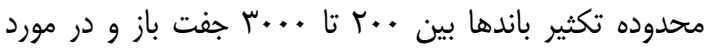

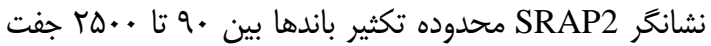

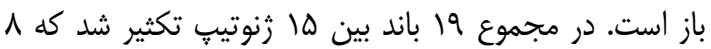

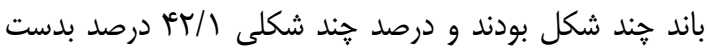

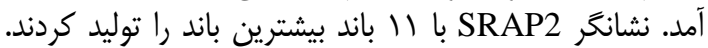

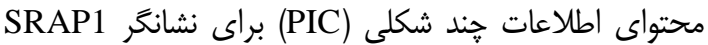

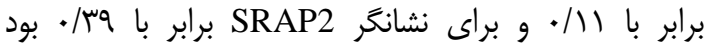

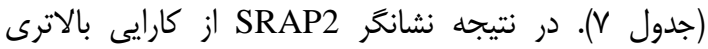

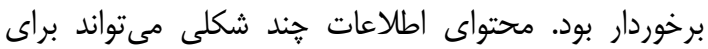




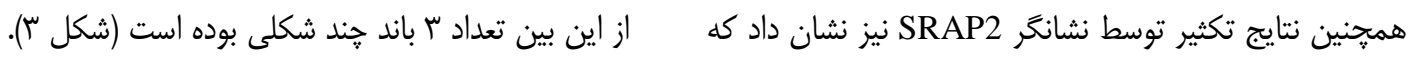

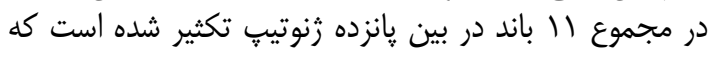

جدول V- نشانگرهاى SRAP استفاده شده و نتايج تكثير آنها در بين ارقام گندم Table 7. SRAP primers used and amplification results between wheat cultivars

\begin{tabular}{|c|c|c|c|c|}
\hline $\begin{array}{c}\text { محتواى اطلاعات هند شكل } \\
\text { (PIC) }\end{array}$ & درصد باندهاى خند شكل & تعداد باند هند شكل & تعداد باند توليد شده & نام نشانگر \\
\hline$\cdot / 111$ & ST/D & $\Delta$ & $\wedge$ & SRAP 1 \\
\hline . & TV/TV & r & 11 & SRAP 2 \\
\hline
\end{tabular}

Table 8. Jaccard similarity matrix method

جدول ^- ماتريس تشابه به روش جاكارد بين ارقام گَندم مورد مطالعه

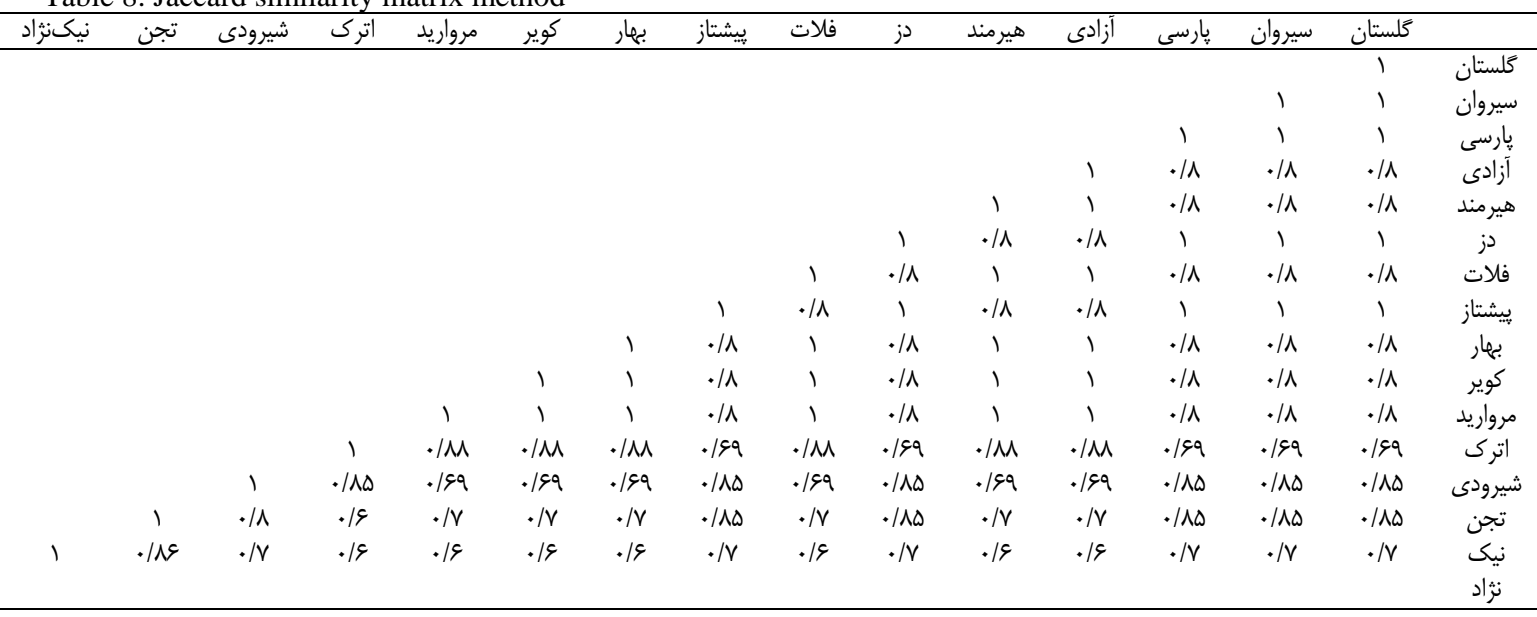

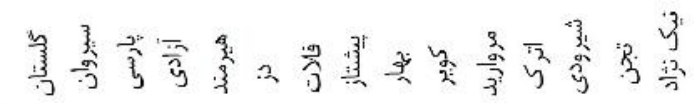
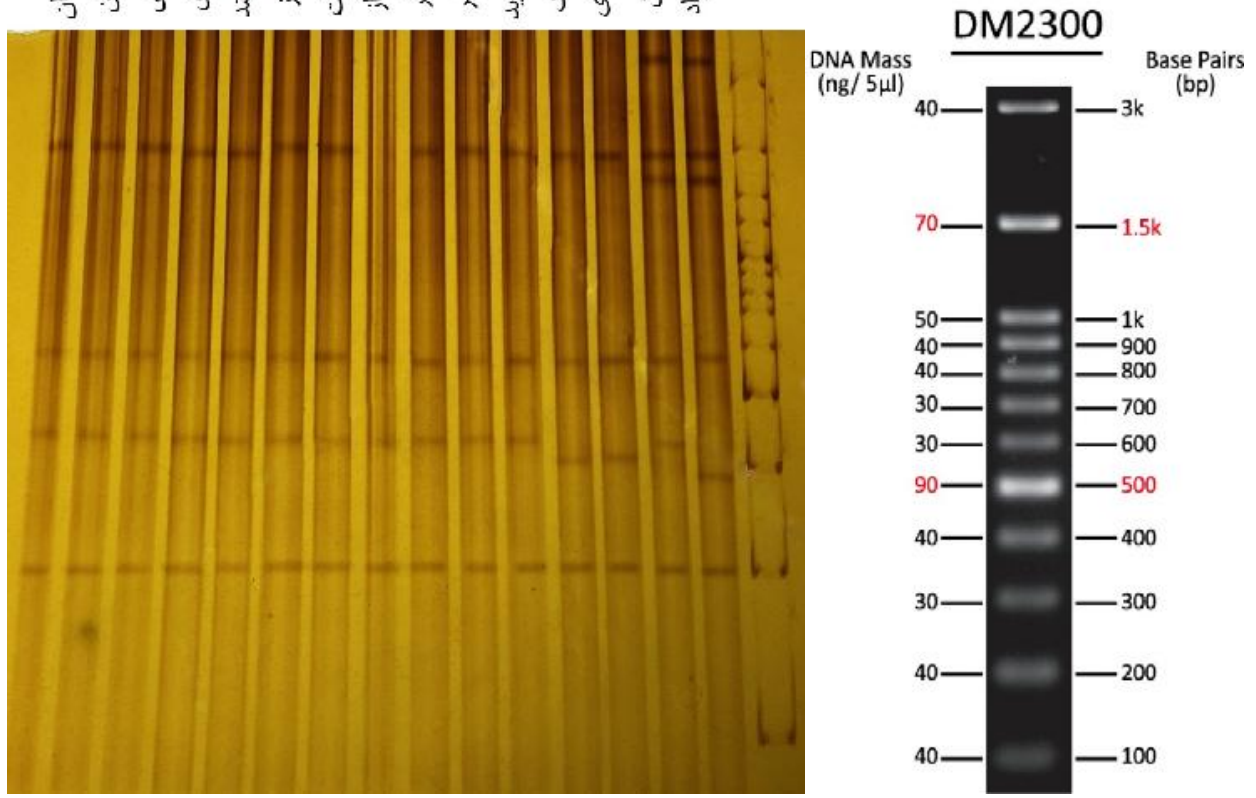

شكل r- الخوى باندى حاصل از تكثير بوسيله نشانحر SRAP1Band 100 bp+3k DNA Ladder ،SRAP1 Figure 2. Banding pattern of the amplified using SRAP1 marker 


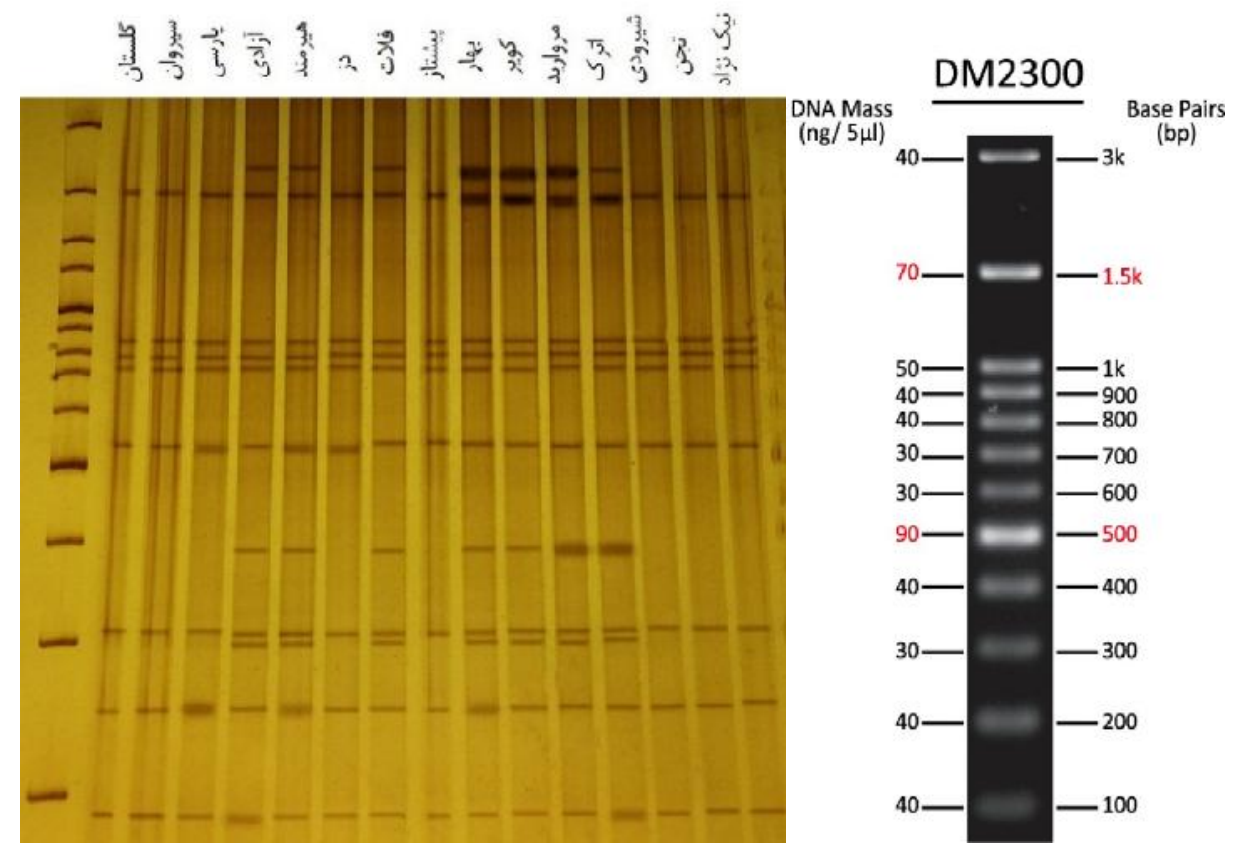

شكل سـ- الخوى باندى حاصل از تكثير بوسيله نشانحر ExcelBand 100 bp+3k DNA Ladder ،SRAP2 Figure 3. Banding pattern of the amplified using SRAP2 marker

يك قرار كرفتند از نظر صفت كيفيت نانوايى، بجز رقم دز

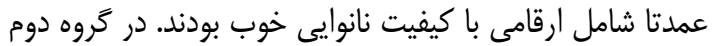

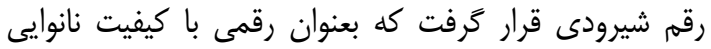

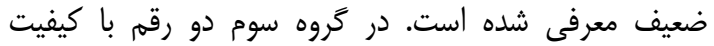

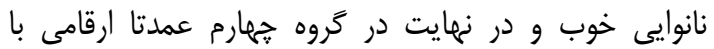

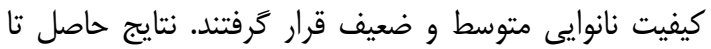

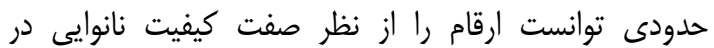

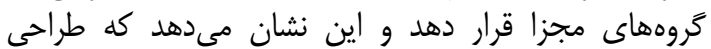

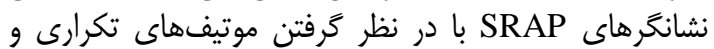

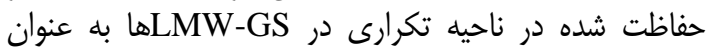

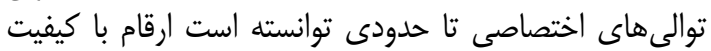

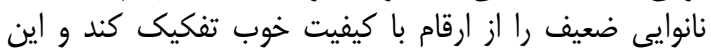

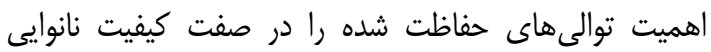

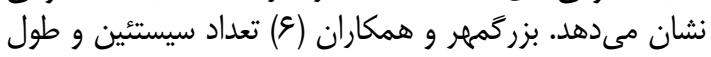
نواحى تكرارى را به عنوان دو عامل موثران دران در كيفيت معرفى سولى

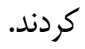

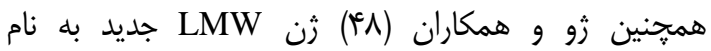

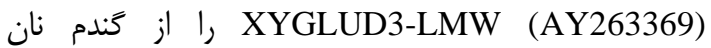
همسانهسازى كردند. نتايج نشان داد كه يروتئين إنهاى حاصل

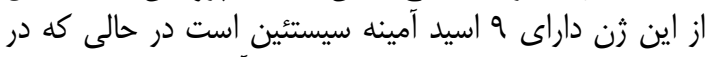

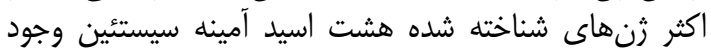

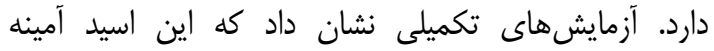
سيستئين اضافى بطور معنى دارى باعث افزايش خصائ خصوصيات كيفى LMW شده است.
دليل استفاده از توالى CCGG در آغازگر رفت، حضور

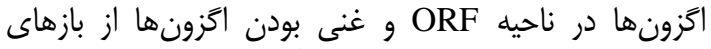

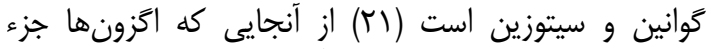

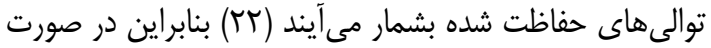

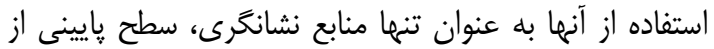

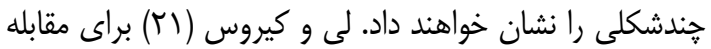

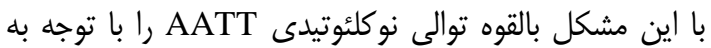

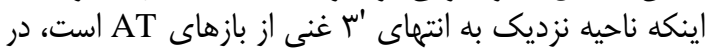

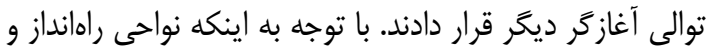

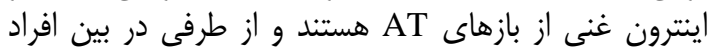

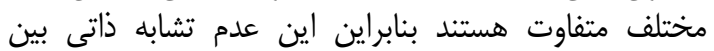

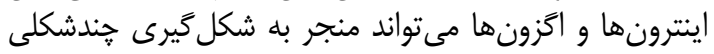

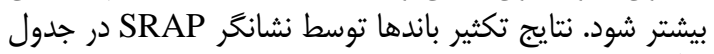
V آمده است.

آناليز نتايج زلهای يلى بلى آكريل آميد با استفاده از نرمافزار

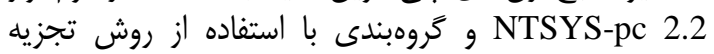

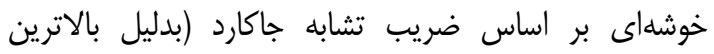

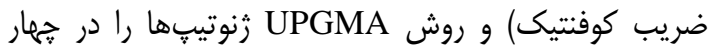

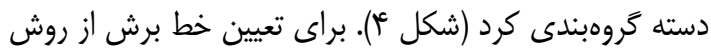
2D

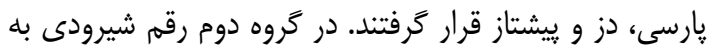

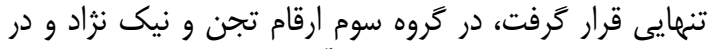

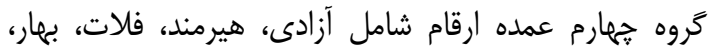

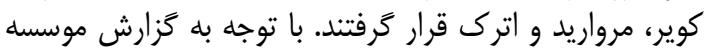

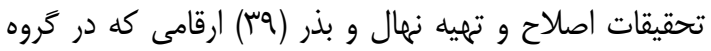




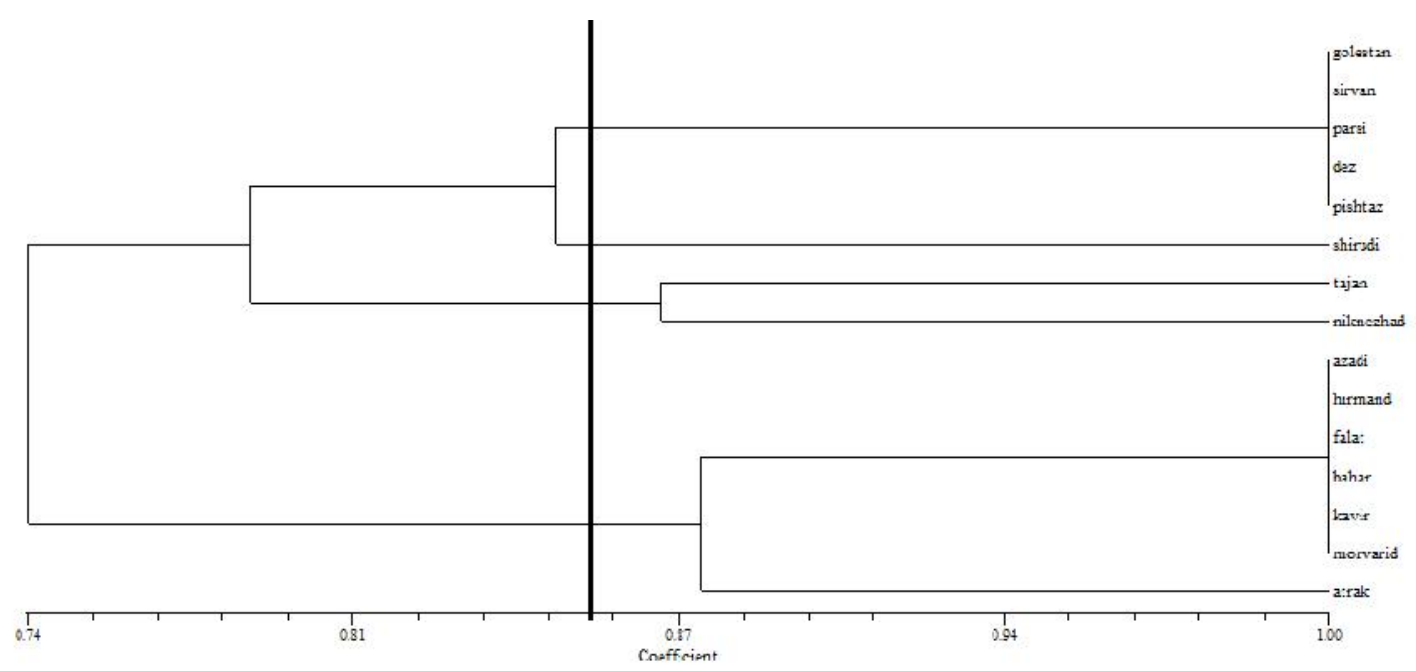

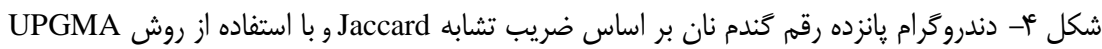
Figure 4. Dendrogram based on Jaccard coefficient using UPGMA method

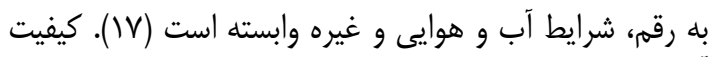

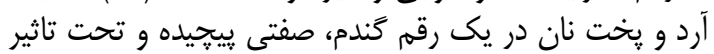

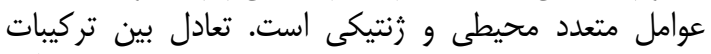

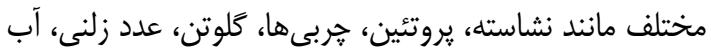

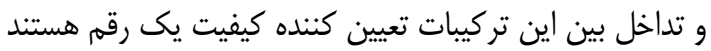

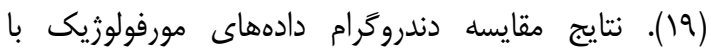

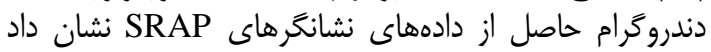

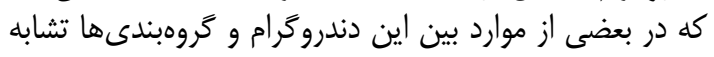

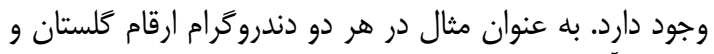

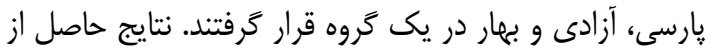

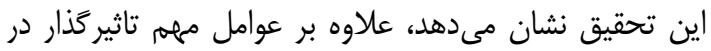

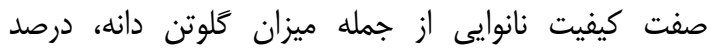

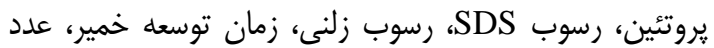

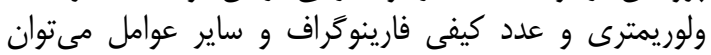

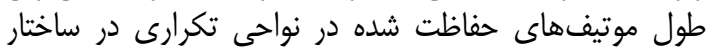

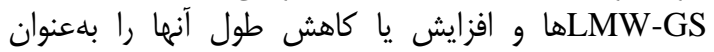

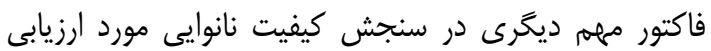

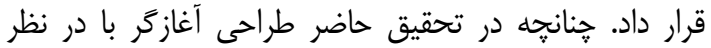

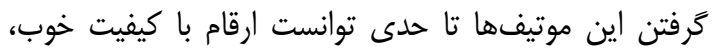
متوسط و ضعيف را از يكديخر تفكيك كند تواند

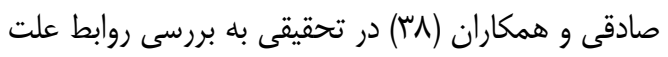

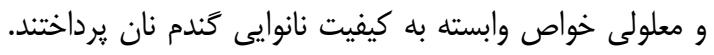

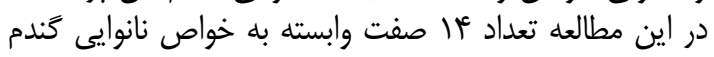

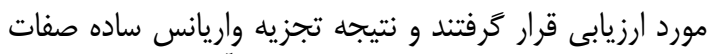

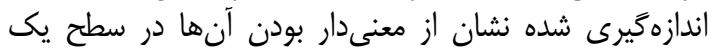

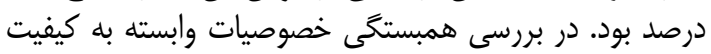

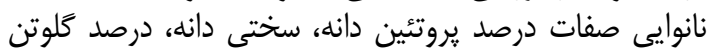

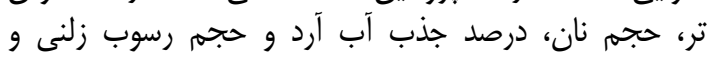

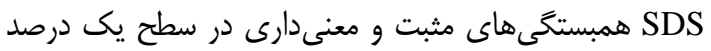

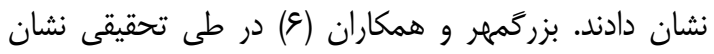

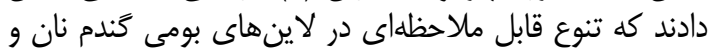

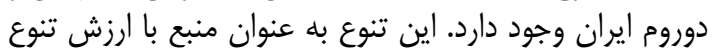

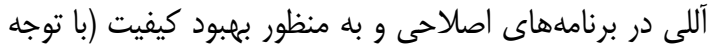

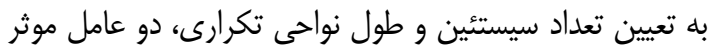

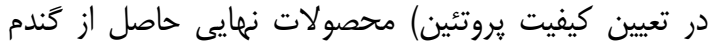

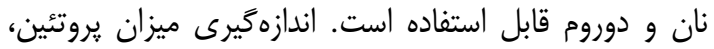

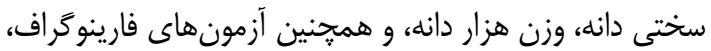

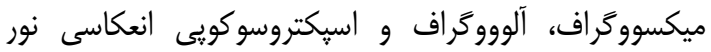

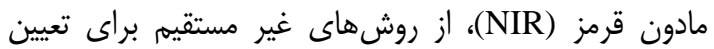

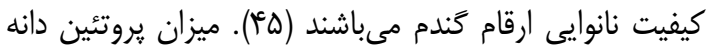

منابع

1. Aghaee-Sarbaze, M. 2012. Agronomic Traits in Durum wheat variety. Journal of Seed and Plant Improvement, 1(3): 481-502 (In Persian).

2. Alvin, C.R. and F.C. William. 1995. Methods of multivariate analysis. Wiley press. $800 \mathrm{w}$.

3. Arzani, A. 1999. Breeding of crop plants. Isfahan University Press. 320 w.

4. Babae Zarrch, M., M. Fatookian and S. Mahmudi. 2013. Assessment of genetic diversity morphological traits wheat using multivariate. Journal of plant breeding agricultural, 5(1) (In Persian).

5. Bahrae, C. 2003. Iranian bread wheat quality assessment based on glutenin subunits heavy. Journal of Crop Science, 5: 3-17 (In Persian).

6. Bozorgmehr, A., J. Ahmadi, F. Shahinnia, Kh. Razavi, G. Njafian and T. Lohrasebi. 2014. Evaluation of allelic variation for low molecular weight glutenin subunits using DNA specific markers in wheat landraces. Journal of Modern Genetics, 9(4): 439-450 (In Persian).

7. Cassidy, B.G., J. Dvorak and O.D. Anderson. 1998. The wheat low molecular weight glutenin genes: characterization of six new genes and progress in understanding gene family structure. Theoretical and Applied Genetics, 96: 743-750. 
8. Collaku, A. and S.A. Harrison. 2002. Losses in wheat due to water logging. Crop Science, 42: 444450 .

9. D’Ovidio, R., C. Marchitelli, L. Ercoli Cardelli and E. Porceddu. 1999. Sequence similarity between allelic Glu-B3 genes related to quality properties of durum wheat. Theoretical and Applied Genetics, 98: 455-461.

10. D'ovidio, R. and S.M. Masci. 2004. The low-molecular-weight glutenin subunits of wheat gluten. Journal of Cereal Science, 39(1): 321-339.

11. Doyle, J.J. and J.L. Doyle. 1987. A rapid DNA isolation procedure for small quantities of fresh leaf tissue. Phytochemistry Bulletin, 19: 11-15.

12. Farahani, A. and A. Arzani. 2006. The study of genetic diversity among durum wheat and F1 generation using agronomic traits. Journal of Agriculture, 4: 341-354 (In Persian).

13. Fernando, R., R. Cuillenportal, N. Obert, S. Qingwnxueaudkent and M. Eskridge. 2006. Compensatory mechanisms associated with the effect of spring wheat seed size and wild oat competition. Crop Science, 46: 935-945.

14. Gill, B.S., R. Appels, A.M. Botha-Oberholster, C.R. Buell, J.L. Bennetzen, B. Chalhoub and B. Keller. 2004. A workshop report on wheat genome sequencing international genome research on wheat consortium. Genetics, 168(2): 1087-1096.

15. Halajian, M. and B. Naserian. 2007. Review and compare amino acid sequences $\mathrm{x}$ and $\mathrm{y}$ types glutenin subunits loci $1 \mathrm{D}$ controller bread quality wheat. 12th Iranian Biotechnology Conference, Tehran.

16. Harberd, N.P., D. Bartels and R.D. Thompson. 1985. Analysis of the gliadin multigene loci in bread wheat using nullisomic-tetrasomic lines. Molecular and General Genetics, 198: 234-242.

17. Iran-Nejad, H. and N. Shahbaziyan. 2005. Cereal cultivation. Wheat. Karenoo Publications.Tehran, Iran, 272 pp (In Persian).

18. Jackson, E.A., L.M. Holt and P.I. Payne. 1983. Characterisation of high molecular weight gliadin and low-molecular-weight glutenin subunits of wheat endosperm by two-dimensional electrophoresis and the chromosomal localization of their controlling genes. Theoretical and Applied Genetics, 66: 29-37.

19. Johansson, E., G. Svensson and W.K. Heneen. 1998. Genotype and environmental effect on factors influencing bread-making quality. In: A. E. Slinkard ed. Proc. 9th Intl. Wheat Genetics Symp, 4: 175177.

20. Lee, M. 1995. DNA markers and plant breeding programs. Advances in Agronomy, 55:265-344.

21. Li, G. and C.F. Quiros. 2001. Sequence-related amplified polymorphism (SRAP), a new marker system based on a simple PCR reaction: its application to mapping and gene tagging in Brassica. Theoretical and Applied Genetics, 103: 455-461.

22. Li, W., Z. Gao, Y. M. Wei, Z. E. Pu, G. Y. Chen, Y. X. Liu, H. P. Chen, X. J. Lan and Y. L. Zheng. 2012. Genetic variations of m-type LMW-GS genes and their associations with dough quality in Triticum turgidum ssp. Turgidum landraces from China. African Journal of Agricultural Research, 7: 2025-2033.

23. Lin X., S. Kaul, S. Rounsley, T. Shea and M.I. Benito. 1999. Sequence and analysis of chromosome 2 of the plant Arabidopsis thaliana. Nature, 402: 761-767.

24. Martinek, P., M. Vinterova, I. Burešová and T. Vyhnanek. 2008. Agronomic and quality characteristics of triticale (X Triticosecale Wittmack) with HMW glutenin subunits 5+10. Journal of Cereal Science, 47(1): 68-78.

25. Masci, S., D. Lafiandra, E. Porceddu, E.J.L. Lew, H.P. Tao, D.D. Kasarda. 1993. D-glutenin subunits: N-terminal sequences and evidence for the presence of cysteine. Cereal Chemistry, 70: 581-585.

26. Masci, S., E.J.L. Lew, D. Lafiandra, E. Porceddu and D.D. Kasarda. 1995. Characterization of lowmolecular-weight glutenin subunits in durum wheat by RP-HPLC and N-terminal sequencing. Cereal Chemistry, 72: 100-104

27. Masci, S., L. Rovelli, D.D. Kasarda, W.H. Vensel and D. Lafiandra. 2002. Characterisation and chromosomal localization of C-type low molecular- weight glutenin subunits in the bread wheat cultivar Chinese Spring. Theoretical and Applied Genetics, 104: 422-428.

28. Mirakhoondi, N. 2001. Study of Variation of Quantitative Traits and Their relationships with yield under drought conditions and irrigation and the best indicator of drought tolerance in durum wheat. Master's Thesis. School of Agriculture. University of Tehran. Karaj, Iran (In Persian).

29. Mousavi shabestari, M. 2007. Check wheat yield in 21 cold areas. Master's Thesis. Islamic Azad University, Tabriz, Iran (In Persian).

30. Nei, M. 1973. Analysis of gene diversity in subdivided populations Proceedings of the National Academy of Sciences of the United States of America, 70: 3321-3323.

31. Pahlevani, S., A. Izanloo, S. Parsa and M.GH. Ghaderi. 2016. Association between grain quality traits and SSR molecular markers in some bread wheat genotypes. Journal of Crop Breeding, 8(19): 25-36 (In Persian).

32. Payne, P.I., E.A. Jackson, L.M. Holt. 1984. The association between ggliadin 45 and gluten strength in durum wheat varieties. A direct causal effect on the result of genetic linkage. Journal of Cereal Science, 2: 73-81. 
33. Payne, P.I., L.M. Holt, M.G. Jarvis and E.A. Jackson. 1985. Twodimensional fractionation of the endosperm proteins of bread wheat (Triticum aestivum): biochemical and genetic studies. Cereal Chemistry, 62: 319-326.

34. Quiros, C.F., F. Grellet, J. Sadowsk, T. Suzuki, G. Li and T. Wroblewski. 2001. Arabidopsis and Brassica comparative genomics: sequence, structure and gene content in the ABII-Rps2-Ck1 chromosomal segment and related regions. Genetics.

35. Rafalski, J.A., J.M. Vogel, M. Morgante, W. Powell, C. Andre and S. Tingey. 1996. Non-mammalian genome analysis: a practical guide. Academic Press, New York, 75-134.

36. Rashidi, V., A. Majidi, V. Mohammadisa and M. Moghadam Vahed. 2007. Determine the genetic relationships of durum wheat lines by cluster analysis and identify morphological traits each group. Journal of Iran Agricultural Sciences, 13(2): 439-450 (In Persian).

37. Sabelli, P. and P.R. Shewry. 1991. Characterization and organization of gene families at the Gli-1 loci of bread and durum wheat. Theoretical and Applied Genetics, 83: 428-434.

38. Sadeghi, F. and H. Dehghani. 2016. Study of correlation coefficients and factors analysis of bread making quality attributes in bread wheat. Journal of Crop Breeding, 8(19): 1-8 (In Persian).

39. Seed and Plant Improvement Institute. 2015. Introduced cultivars food security and health, volume 1. Agricultural Extension and Education Research Organization (In Persian).

40. Shafaedin, S. and B. Yazdi Samadi. 1994. Genetic diversity and geographic wheat mills native to Central Iran. Journal of Iran Agricultural Sciences, 25: 61-77 (In Persian).

41. Shahid Masood, M., A. Javaid, M. Ashiq Rabbani and R. Anwar. 2005. Phenotypic diversity and trait association in bread wheat (Triticum aestivum L.) Landraces from Baluchistan, Pakistan. Pakistan Journal of Botany, 37(4): 949-957.

42. Shariat, F., S.A. Mohammadi, M. Norouzi and M. Valizadeh. 2015. Allelic diversity of low molecular weight glutenin subunit at Glu-A3, Glu-B3 and Glu-D3 loci in Iranian spring bread wheat landraces. Iranian Journal of Crop Sciences, 17(1): 74-87 (In Persian).

43. Shewry, P.R., N.G. Halford and A.S. Tatham. 1989. The high molecular weight subunits of wheat, barley and rye. In: Miflin, B.J., (Ed.), Genetics, Molecular Biology, Chemistry and Role in Wheat Gluten Structure and Functionality, Oxford Survey Plant Molecular and Cellular Biology, vol. 6. University Press, New York, 163-219.

44. Sidwell, R. J., E.L. Smith and R.W. Mcnew. 1975. Inheritance and interrelationships of grain yield and selected yield related traits in a hard red winter wheat cross. Crop Science, 16: 650-65.

45. Sissons, M.J., B. Osborne and S. Sissons. 2006. Application of near infrared reflectance spectroscopy to a durum wheat breeding programme. Journal of Near Infrared Spectroscopy, 14: 17-25.

46. Toosi Mojarad, M. and M. Bihamta. 2007. Check wheat grain yield and other traits through by principal component. Journal of Agricultural Science, 2: 1-97 (In Persian).

47. Vaezi, S. 1999. Genetic diversity and geographic diversity index and quantitative local collection of durum wheat mills in Iran. Master's Thesis. School of Agriculture. University of Tehran. Karaj, Iran, (In Persian).

48. Xu H., R.J. Wang, X. Shen, Y.L. Zhao, G.L. Sun, H.X. Zhao and A.G. Guo. 2006. Functional properties of a new low molecular- weight glutenin subunit gene from a bread wheat cultivar. Theoretical and Applied Genetics, 113: 1295-1303.

49. Zhen, S., C. Han, C. Ma, A. Gu, M. Zhang, X. Shen, X. Li and Y. Yan. 2014. Deletion of the lowmolecular-weight glutenin subunit allele Glu-A3a of wheat (Triticum aestivum L.) significantly reduces dough strength and breadmaking quality. BMC Plant Biology, 14: 367-384. 


\title{
Study of Morphological Traits and Genetic Diversity of low Molecular Wight- Glutenin Subunits in Some Bread Wheat Cultivars using SRAP Markers
}

Mohammad Parand ${ }^{1}$, Ahad Yamchi ${ }^{2}$, Hassan Soltanloo ${ }^{3}$ and Khalil Zaynalinejad ${ }^{4}$

\author{
1, 3 and 4- PhD. Student in Nuclear Agriculture, Associate Professor and Assistant Professor, Gorgan \\ University of Agricultural Sciences and Natural Resources \\ 2- Assistant Professor, Gorgan University of Agricultural Sciences and Natural Resources \\ (Corresponding author: yamchi@gau.ac.ir) \\ Received: April 19, $2017 \quad$ Accepted: July 4, 2017
}

\begin{abstract}
Baking quality is one of the most important traits in wheat quality breeding. In the present study, allelic diversity of the genes encoding glutenin with low molecular weight (LMW-GS) was evaluated in 15 good, average and poor cultivars in term of baking quality using SRAP markers. Further, morphological traits, including 100-seed weight, spike number per plot, seed number per spike, plant height and spike length were investigated in order to identify possible correlation with molecular markers. In this experiment, two SRAP markers were designed based on repetitive region in LMW-GS. The ANOVA results of morphological traits revealed that all cultivars were differently at 0.01 level. Additionally, the correlation analysis between grain yield and other morphological traits indicated a high correlation between yield and spike number per plot. In morphological traits, the cultivars were grouped in three cluster using WARD method and CCC plot cutoff. The product size ranged from 200 to $3000 \mathrm{bp}$ and 90 to $2500 \mathrm{bp}$ for SRAP1 and SRAP2 markers, respectively. In total, 19 bands were produced among the cultivars and polymorphic percentage was 42.1. SRAP2 produced the highest number of bands (11). Polymorphic information content (PIC) was 0.11 and 0.39 for SRAP1 and SRAP2 markers, respectively. Cluster analysis based on Jaccard's coefficient and UPGMA algorithm by NTSYSpc 2.2 software related that the cultivars were allocated in four clusters. The results showed that SRAP marker could approximately group the cultivars according to baking trait and this classification can be compared with morphological data.
\end{abstract}

Keywords: Wheat Bread, Quality Bakery, Morphological traits, SRAP marker 